\title{
STARVATION AND OVERFEEDING STRESS ON MICROBIAL ACTIVITIES IN HIGH-SOLIDS HIGH-YIELD METHANOGENIC DIGESTERS
}

\author{
David B. Hedrick, ${ }^{*}$ Arpad Vass, ${ }^{*}$ Brian K. Richards, $†$ William J. Jewell, ${ }^{\dagger}$ \\ JAMES B. GUCKERT* and DAVID C. WHITE* + \\ ${ }^{*}$ Institute for Applied Microbiology, University of Tennessee, Knoxville, TN 37932-2567, U.S.A. \\ †Department of Agricultural and Biological Engineering, Cornell University, Ithaca, NY 14853, U.S.A. \\ $\ddagger$ Department of Microbiology, University of Tennessee, Knoxville, TN 37996-0845 and \\ Environmental Sciences Division, Oak Ridge National Laboratory, Oak Ridge, TN 37831, U.S.A.
}

(Received 31 August 1990; accepted 21 May 1991)

\begin{abstract}
Methane production from a high-solids digester was significantly decreased by both feedstock starvation and overfeeding. Both starvation and overfeeding also induced significant decreases in acetate turnover, acetate incorporation into methane, and in the ratio of triglyceride to polar lipid. The physiological status ratio of ${ }^{14} \mathrm{C}$-acetate incorporated into poly- $\beta$-hydroxybutyrate to polar lipid was unchanged by either treatment. Digester $\mathrm{pH}$, and acetate and ammonia concentrations were unchanged by starvation. Overfeeding decreased the $\mathrm{pH}$, and greatly increased ammonia and acetate, creating a toxic environment. The rate of ${ }^{14} \mathrm{C}$-acetate incorporation into total lipid significantly increased with starvation but significantly decreased with overfeeding. The ratio of ${ }^{14} \mathrm{C}$-acetate incorporated into eubacterial and eukaryotic fatty acids to methanogen ether lipids significantly increased with starvation and significantly decreased under overfeeding. This study provides one of the most thorough descriptions currently available for starvation and overfeeding stress effects on methanogenic digester performance, including specific eubacterial and archaebacterial activities. These results provide important insight into methanogenic digester operating parameters for stable biomass-to-methane yields.
\end{abstract}

Keywords-Metabolic status, methane production, methanogenesis, microbial activities, poly- $\beta$-hydroxyalkanoate, radiolabel methods, triglycerides.

\section{INTRODUCTION}

Signature lipid biomarkers for microbial biomass, community structure and nutritional status have provided insight into the microbial ecology of many environments, ${ }^{1}$ including the conversion of biomass to methane. ${ }^{2,3}$ The in situ metabolic activities of a microbial community can be observed by the use of radiotracer techniques. In this work, acetate labeled in the methyl carbon $\left({ }^{14} \mathrm{C}\right.$-2-acetate) was used to probe microbial growth, synthesis and utilization of acetate, and metabolic status in a high-solids high-yield methanogenic digester.

Acetate has a central position in the pathways of anaerobic mineralization of biomass. ${ }^{4}$ It and carbon dioxide are the major products of the hydrolysis and fermentation of carbohydrate substrates. ${ }^{5}$ Between 60 and $70 \%$ of the methane produced in an anaerobic biomass digester is derived from acetate. ${ }^{6}$ Acetate is readily incorporated into lipids by methanogens and many

Please address correspondence to: David B. Hedrick, Institute for Applied Microbiology, 10515 Research Drive, Suite 300, Knoxville, TN 37932-2567, U.S.A. eubacteria. The patterns of radiolabeled acetate incorporation into lipid, methane, and carbon dioxide were used to investigate changes in the microbial cooperative metabolism required for methane production within these digesters.

The pseudo first-order rate constant for the transformation of acetate $\left(k_{\mathrm{Ac}}\right)$ was calculated from the disappearance of radiolabeled acetate from the digester. The percent of ${ }^{14} \mathrm{C}$ incorporated into total extractable lipids per hour $\left(k_{\mathrm{TL}}\right)$ is a measure of microbial growth and substrate availability. ${ }^{7}$ The percent of total label incorporated into methane per hour $\left(k_{\mathrm{CH} 4}\right)$ and carbon dioxide per hour $\left(k_{\mathrm{CO} 2}\right)$ are measures of energyyielding metabolic activities. ${ }^{5}$

The polar lipid fraction of the total lipids was analyzed for the ether lipids (PLEth) of archaebacteria and the fatty acids (PLFA) of eubacteria and micro-eukaryotes. ${ }^{8}$ These polar lipid components are measures of microbial biomass. ${ }^{9}$ ${ }^{14} \mathrm{C}$-acetate incorporation into these compounds was expressed as the ratio incorporated into PLFA to that into PLEth (PLFA/PLEth), for a comparison of eubacterial plus eukaryote versus methanogen lipid synthesis. 
Two classes of microbial carbon storage compounds were assayed as measures of microbial metabolic status-the poly- $\beta$-hydroxyalkanoates (PHA) and the triglycerides (TG). Many bacteria synthesize PHA in response to the metabolic stress of nutrient limitation in the presence of adequate carbon and electron donor/acceptor substrates. This leads to unbalanced bacterial growth and PHA accumulation. ${ }^{10,11}$ Microeukaryotes synthesize TG as carbon and energy storage compounds under similar conditions. ${ }^{12}$ The metabolic status of the micro-eukaryote or prokaryote components of the microbial community was expressed as a ratio by normalizing to the polar lipid content (PL), a measure of biomass. The ratios PHA/PL and TG/PL were used to monitor the nutritional status of the prokaryotes and micro-eukaryotes, respectively.

Two experimental methanogenic digesters were chosen for this work because of their innovative digester design and potential for industrial application. They were thermophilic $\left(55^{\circ} \mathrm{C}\right)$, and operated at unusually high percent solids $(23 \%), \mathrm{pH}(7.8)$, and productivity $\left(61 \cdot \mathrm{kg}^{-1}\right.$ $\mathrm{day}^{-1}$, on a liter of methane per $\mathrm{kg}$ reactor contents basis). This digester design ${ }^{13}$ has achieved sustained methane production rates of $7.5 \mathrm{l} \cdot \mathrm{kg}^{-1}$ day '. This rate is approximately 4 or 5 times the maximum production rates found in low solids digesters $\left(1.51 \mathrm{~kg}^{-1} \mathrm{day}^{-1}\right.$ and $1.81 \cdot \mathrm{kg}^{-1}$ $\left.\operatorname{day}^{-1}\right) .^{14}$

\section{MATERIALS AND METHODS}

The chloroform, acetone, methanol, hexane, diether, and ammonium hydroxide used were analytical grade (Baxter Scientific, McGaw Park, IL). Stearic acid, 1,2-di- $O$-hexadecylglycerol, and tristearin lipid standards were from Sigma Chemical Co., St. Louis, MO. The scintillation fluid was Ecolume (ICN Biomedicals, Irvine, CA). Liquid scintillation counting (LSC) was done on a LKB 1212 Rackbeta (Gaithersburg, MD) using the channels ratio correction method.

\subsection{High-solids methanogenic digesters}

The high-solids digesters were operated at the Department of Agricultural and Biological Engineering of Cornell University. ${ }^{13}$ Each digester consisted of a sealed 201 polypropylene carboy with $5 \mathrm{~kg}$ of digester material incubated statically at $55^{\circ} \mathrm{C}$. They were fed every Monday, Wednesday, and Friday by replacing 5 to $15 \%$ of the digester contents (depending upon the feeding interval and the loading rate).
The feed was a 1:1 mixture of $\alpha$-cellulose (Sigma Chemical Co.) and milled dried sorghum (Sorghum bicolor, Stanford Seeds variety X9204). Moisture was maintained with a trace mineral solution ${ }^{13}$ including $\mathrm{S}, \mathrm{Fe}, \mathrm{P}, \mathrm{Ni}, \mathrm{Co}$, and Mo. Ammonia was supplemented at the rate of 32 to $40 \mathrm{mg} \mathrm{N} \cdot \mathrm{kg}^{-1} \mathrm{~d}^{-1}$. Digester contents were maintained between 25 to $32 \%$ total solids, resulting in a very moist solid material with no free water.

\subsection{Healthy and starved digester treatments}

The first high-solids digester (HS1) had an organic loading rate (OLR) of 18 grams volatile solids per kilogram wet digester contents per day ( $\mathrm{gVS} \cdot \mathrm{kg}^{-1} \mathrm{day}^{-1}$ ). In this experiment, HSl was sampled before feeding, and 6,24, and $48 \mathrm{~h}$ after feeding in order to observe changes in the microbial community over the feedstock utilization cycle. Samples of the digester contents were taken for measurements of digester performance and for incubation with radiolabeled acetate.

\subsection{Overfed digester treatment}

Another high-solids digester (HS2) was operated in the same way, except at a higher OLR of $24 \mathrm{gVS} \cdot \mathrm{kg}^{-1} \mathrm{day}^{-1}$. Samples were taken $24 \mathrm{~h}$ after feeding for comparison of this overfed digester community at maximum gas production with the "healthy" HSI community at maximum gas production $(24 \mathrm{~h})$.

\subsection{Digester performance parameters}

Digester gas production rates were monitored continuously using GCA Precision Scientific wet test meters. Gas volumes were converted to dry gas at $0^{\circ} \mathrm{C}$. Methane contents were determined using a Gow-Mac model 580 thermal conductivity detector gas chromatograph, with a Poropak $\mathrm{Q}$ column. The $\mathrm{pH}$, and ammonia and acetate concentrations of the high solids digesters were each determined on separate samples. Sample $\mathrm{pH}$ was determined by diluting the semisolid effluent 1:1 with distilled water and measurement with a $\mathrm{pH}$ electrode. Ammonia concentrations were determined by Kjeldahl distillation. VFA analysis was carried out with a gas chromatograph-flame ionization detector using a $15 \mathrm{~m}$ Nukol (Supelco, Inc.) wide-bore capillary column. All digester loading rates, methane production rates and analyte concentrations are expressed as per kilogram of wet digester contents. 


\subsection{Sampling for radiolabel incubation}

A $100 \mathrm{~g}$ (wet weight) sample of the digester material was placed in a small plastic container under a headspace of nitrogen. $2 \mathrm{ml}$ of material was gently packed into the open end of a $3 \mathrm{ml}$ plastic syringe that had the Luer-lock end cut off. Care was taken not to pack the material so tightly that liquid was expressed and to avoid unnecessary exposure to oxygen. The sample was immediately placed in a pre-weighed pressure tube (Bellco Glass Inc., Vineland, NJ) with $0.74 \mu \mathrm{Ci}$ of ${ }^{14} \mathrm{C}$-2-acetate $\left(50 \mathrm{mCi} \cdot \mathrm{mmol}^{-1}\right.$, New England Nuclear, Boston, MA) in $1 \mathrm{ml}$ sterile, anaerobic, deionized water, and vigorously shaken. The precise weight of sample was determined by difference. For each sampling time, 12 radiolabel tubes were prepared. Triplicate tubes were incubated with radiolabel for either $0,0.5,3$, or $24 \mathrm{~h}$ at $55^{\circ} \mathrm{C}$ before inhibiting with $5 \mathrm{ml}$ formalin. Tubes to be inhibited at time $=$ $0 \mathrm{~h}$ had the formalin added before incubation. After inhibition, the tubes were immediately frozen until analysis.

\subsection{Headspace analysis}

For the determination of total methane and labeled methane and carbon dioxide, the tubes were thawed to room temperature and $0.2 \mathrm{ml}$ aliquots of the headspace were injected into a Shimadzu GC-8A gas chromatograph equipped with a Carbosieve 8000 column and a thermal conductivity detector. Radiolabeled methane and carbon dioxide were determined with a Packard Model 894 gas proportional counter connected to the gas chromatograph effluent. Retention time and concentration standards for methane, carbon dioxide, and ${ }^{14} \mathrm{C}$-carbon dioxide were made by diluting each gas with nitrogen in sealed serum bottles. Calibration curves were linear over the range used. The counting efficiency for ${ }^{14} \mathrm{C}$ determined for carbon dioxide $(65 \%)$ was used for methane. Immediately after gas chromatographic analysis, the pressure tubes were opened and the $\mathrm{pH}$ measured in order to determine the partition coefficient for carbon dioxide between aqueous and gas phases. The pressure tubes were then refrozen until analysis of labeled lipids.

\subsection{Radiolabeled lipid analysis}

For analysis of the label incorporated into lipids, the tubes were thawed and the contents extracted by the method of Bligh and Dyer ${ }^{15}$ as modified to include phosphate buffer. ${ }^{16}$ The sample was transferred from the pressure tube into a $250 \mathrm{ml}$ separatory funnel with $37.5 \mathrm{ml}$ of chloroform, $75 \mathrm{ml}$ of methanol, and $30 \mathrm{ml}$ of phosphate buffer $\left(50 \mathrm{~mm} \mathrm{PO}_{4}, \mathrm{pH}=7.4\right)$. The single-phase solvent was allowed to extract for at least $2 \mathrm{~h}$. Additional chloroform and water were then added ( $37.5 \mathrm{ml}$ each), which separated the organic and aqueous phases. The organic phase containing the lipids was collected and the solvent removed with a rotary evaporator at $37^{\circ} \mathrm{C}$. The total lipid extract was dissolved in $1 \mathrm{ml}$ of chloroform, $10 \%$ was reserved for LSC, and the solvent was removed as above. The volume of the aqueous phase was measured and a $1 \mathrm{ml}$ aliquot taken for LSC.

The lipid extract was separated into neutral lipid, glycolipid, and polar lipid fractions by silicic acid column chromatography. ${ }^{17}$ One g of silicic acid (Unisil, 100-200 mesh, Clarkson Chem., Williamsport, PA) was slurried in chloroform and loaded onto a $1 \mathrm{~cm}$ wide disposable pipet plugged with glass wool. Neutral lipids were eluted with $10 \mathrm{ml}$ of chloroform, glycolipids with $10 \mathrm{ml}$ of acetone, and polar lipids with $10 \mathrm{ml}$ of methanol. Solvent was removed from each fraction with a stream of dry nitrogen on a $37^{\circ} \mathrm{C}$ water bath. Ten percent of each fraction was taken for LSC.

The polar lipid fraction was further separated into the diether, tetraether, and fatty acid components. Treating the polar lipid with a strong acid hydrolysis $\left(10 \% \mathrm{HCl}, 100^{\circ} \mathrm{C}, 1 \mathrm{~h}\right)$ freed the polar lipid ester-linked fatty acids (PLFA) as free fatty acids and the phospholipid ethers (PLEth) as ether-alcohols. ${ }^{18}$ The hydrolyzate was neutralized with aqueous $\mathrm{NaOH}, 2 \mathrm{ml}$ of water and $2 \mathrm{ml}$ of hexane:chloroform $(4: 1)$ added, the test tube vigorously mixed, centrifuged, and the upper organic layer transferred to another test tube. The aqueous phase was extracted twice more with hexane:chloroform, the extracts pooled, and the solvent removed with a stream of dry nitrogen on a $37^{\circ} \mathrm{C}$ water bath. $10 \%$ was taken for liquid scintillation counting (LSC).

The fatty acid, diether, and tetraether components of the polar lipid methanolysate were separated by thin layer chromatography on Whatman Linear $K$ plates. The eluent was hexane: diether:ammonia $(80: 20: 2)$. The bands were visualized by exposure to iodine vapors. Tetraether purified from Methanobacterium formicicum, 1,2-di- $O$-hexadecylglycerol, and stearic acid were used as retention standards. The bands corresponding to fatty acid, diether, 
and tetraether were scraped from the TLC plate, eluted into liquid scintillation vials with chloroform:methanol $(1: 1)$, and the solvent removed with a stream of dry nitrogen at $37^{\circ} \mathrm{C}$.

The poly- $\beta$-hydroxyalkanoate (PHA) in the glycolipid fraction was determined by the method of Findlay et al. ${ }^{19}$ The glycolipid was dried on a $1 \mathrm{~cm} \times 4 \mathrm{~cm}$ strip of Whatman $3 \mathrm{M}$ filter paper and fixed in a $100^{\circ} \mathrm{C}$ drying oven for 30 min. Lipids other than PHA were then eluted from the paper by repeated rinsing with ethanol and diethyl ether. The filter paper strips were placed in scintillation vials with $5 \mathrm{ml}$ Ecolume and measured by LSC.

The TG was separated from the neutral lipid fraction by thin layer chromatography with hexane: ethyl ether:acetic acid $(80: 20: 2)$ as the mobile phase on Whatman Linear K TLC plates. Tristearin was used as the retention standard.

\subsection{Statistical analyses}

Each variable was transformed using an algebraic function chosen to minimize the heterogeneity of variance, as tested by the method of Cochran's $C .{ }^{20}$ Analysis of variance was used to determine whether the measured parameters differentiated between treatments. A $95 \%$ confidence level $(\alpha=0.05)$ was used for all tests of statistical significance.

\section{RESULTS}

\subsection{Digester performance parameters}

HS1 had been operated under conditions of stable $\mathrm{pH}$, and methane, carbon dioxide, and volatile fatty acid production rates for over 60 days at the time of sampling. The peak of methane production was routinely observed at $24 \mathrm{~h}$ after feeding. Methane production fell dramatically by $48 \mathrm{~h}$ due to substrate exhaustion. HS1 was considered to be operating at near optimal efficiency. ${ }^{13}$ HS2 had displayed instability, as indicated by falling gas production and increasing volatile fatty acids and ammonia concentrations. The digester's OLR had been rapidly increased following a period of instability and recovery in order to induce a state of overloading. This led to rapid volatile fatty acid (VFA) accumulation and inhibition of the microbial community. Feedings had been suspended for 10 days (during which VFA and ammonia continued to accumulate), but were resumed at the specified rate the day before sampling began. ${ }^{13}$ While the rate of gas production varied from one feeding cycle to the next, the peak of gas production was regularly observed $24 \mathrm{~h}$ after feeding.

The estimates of methane production for these high-solids reactors are shown in Fig. 1A. There was very good agreement between the methane production rates measured on the reactors and those measured in the pressure tube microcosms, except for the $48 \mathrm{~h}$ sampling time, where the in vitro measurement detected a decline in rate, in agreement with observation of digester performance in previous feeding cycles. Methane production rates over the time course were found to vary significantly, especially between the highly active sample at $24 \mathrm{~h}$ and the exhausted sample at $48 \mathrm{~h}$ after feeding. The difference in methane production rate between HS1 and HS2 at $24 \mathrm{~h}$, the healthy and overfed samples, was also significantly different.

The $\mathrm{pH}$ and the ammonia concentration of HS1 (Fig. 1B and 1C) rose slightly (but not significantly) in the first $6 \mathrm{~h}$ after feeding. The acetate concentration (Fig. 1D) was relatively stable. The variation in these parameters was small, and on the same order as the standard deviations in other measured parameters (Figs 1 and 2) for which replication was available, indicating that the environment in HS1 as measured by these parameters was stable over the feeding cycle. HS2 had a much lower $\mathrm{pH}$ than HS1 (Fig. 1B), and much higher ammonia (Fig. 1C), acetate (Fig. 1D), and propionate concentrations (data not shown).

\subsection{Acetate incorporation patterns}

Radiolabel incorporation patterns were determined on HS1 at feeding and 6, 24, and $48 \mathrm{~h}$ after feeding, and on HS2 at $24 \mathrm{~h}$ after feeding, and on HS2 at $24 \mathrm{~h}$ after feeding (Fig. 2). For each time of digester sampling, triplicate radiolabel tubes were incubated for radiolabel utilization/incorporation kinetic analysis (radiolabel incubation times $=0,0.5,3$, or $24 \mathrm{~h}$ ). Label utilization and incorporation measured at $3 \mathrm{~h}$ of radiolabel incubation gave the best approximation of initial radiolabel utilization/ incorporation rates for all digester sampling times. Rates calculated from the difference in label distribution between 0 and $0.5 \mathrm{~h}$ radiolabel incubation (data not shown) were much lower and more variable for all digester sampling times, probably due to the disturbance of sampling (oxygen cxposure, the change in temperature) and the time required for diffusion of the label into the digester material. The fraction of label left in the aqueous phase of the extraction was 


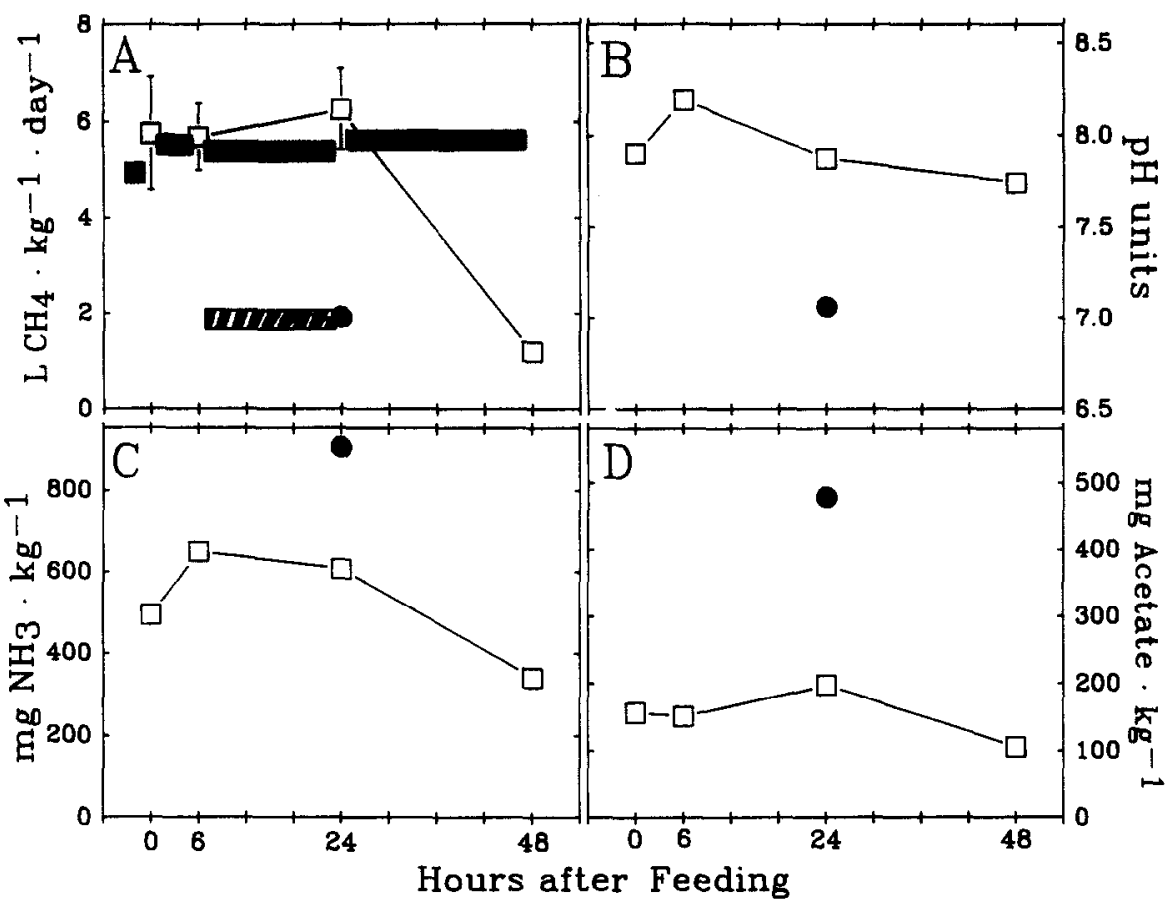

Fig. 1. Digester performance parameters measured on the high solids digesters-methane production rate, $\mathrm{pH}$, and ammonia and acetate concentrations. The horizontal axis is the time after feeding in hours. A: black bars represent methane production of digester HS1 measured by continuous volumetry and gas chromatography, the diagonally striped bar represents methane produced by the overfed digester HS2. A-D: Open squares represent the parameters measured in the radiolabel incubation tubes for HSI and filled circles HS2.

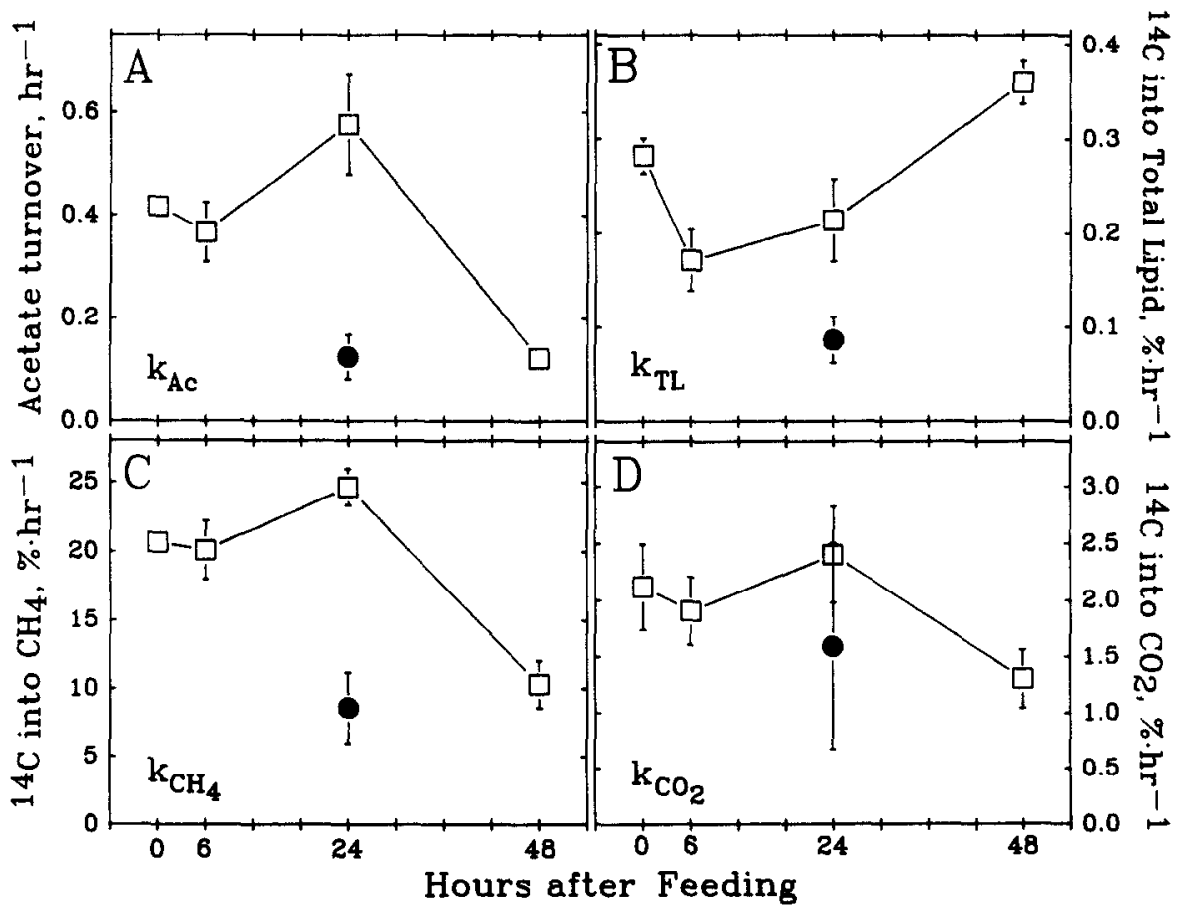

Fig. 2. Activity measures on the high solids digesters. A: acetate turnover rate in units of $h^{-1}$. B-D: incorporation of radiolabeled acetate into total lipids, methane, and carbon dioxide, in units of percent of label incorporated per hour. Average \pm standard deviation, $n=3$. 
$5 \%$ or less after $24 \mathrm{~h}$ of radiolabel incubation. Rates calculated based upon the distribution of label at this time would be incorrect due to exhaustion of the supply of labeled acetate. Furthermore, the lack of significant aqueous label at the end of the radiolabel incubation supports the assumption that the label in the aqueous fraction at $3 \mathrm{~h}$ radiolabel incubation represents untransformed acetate rather than aqueous metabolites. Therefore, the equation ${ }^{21}$

$$
k_{\mathrm{Ac}}=\frac{-\ln \left([\mathrm{Ac}]_{3 \mathrm{~h}} /[\mathrm{Ac}]_{\mathrm{oh}}\right)}{3 \mathrm{~h}}
$$

yields the pseudo first-order rate constant for the loss of acetate, where $[\mathrm{Ac}]_{3 \mathrm{~h}}$ is the concentration of radiolabeled acetatc in the aqueous fraction at $3 \mathrm{~h}$ radiolabel incubation.

The $k_{\mathrm{Ac}}$, in units of per hour, was calculated for each of the HS1 feeding cycle time points and for the HS2 sample at maximum gas production (24 h after feeding) (Fig. 2A). HSl's value of $k_{\mathrm{Ac}}$ initially fell from $0.42 \pm 0.02$ (average \pm standard deviation, $n=3$ ) to $0.37 \pm 0.06$, peaked at $0.58 \pm 0.10$ during maximum gas production ( $24 \mathrm{~h}$ after feeding), and then precipitously fell to $0.12 \pm 0.0148 \mathrm{~h}$ after feeding, equal to that of HS2 at its maximum gas production, $0.12 \pm$ 0.04 . Analysis of variance indicated significant differences in $k_{\mathrm{Ax}}$ between samples taken over the time course of HS1, and between HS1 and HS2 at maximum gas production.

The percent of the added label incorporated into the total lipid extract per hour, $k_{\mathrm{TL}}$ (Fig. 2B), decreased from $0.28 \pm 0.02 \% \cdot h^{-1}$ before feeding to $0.17 \pm 0.03$ at $6 \mathrm{~h}$ after feeding and then increased to $0.21 \pm 0.04$ and $0.36 \pm 0.02$ by 24 and $48 \mathrm{~h}$, respectively. $k_{\mathrm{TL}}$ for HS2 was much less, $0.09 \pm 0.03 \% \mathrm{~h}^{-1}$. Analysis of variance showed significant differences within the time course samples, and between HS1 and HS2.

The rates of incorporation of ${ }^{14} \mathrm{C}$-2-acetate into methane and carbon dioxide were also expressed as percent of the total label per hour, $k_{\mathrm{CH} 4}$ and $k_{\mathrm{CO} 2}$ (Figs 2C and 2D). These measurements showed the same pattern observed in $k_{\mathrm{Ac}}$ : a decrease of activity at $6 \mathrm{~h}$ after feeding, an increase during maximum gas production $(24 \mathrm{~h})$, and a final larger decrease in activity at $48 \mathrm{~h}$ after feeding. The lower rate for HS2 than for HSl was also similar to $k_{\mathrm{Ac}}$. Analysis of variance showed that the differences over the time course were significant for both gasses, and between digesters HS1 and HS2 were significant only for $k_{\mathrm{CH} 4}$.
Table 1. Lipid measures of microbial metabolic status within the methanogenic digester. Radiolabel incorporated from acetate into lipid components expressed as ratios, each expressed as average (standard deviation), $n=3$. Significant difference from the healthy digester is indicated by an asterisk (*), Tukey's HSD at $\alpha=0.05$

\begin{tabular}{|c|c|c|c|}
\hline & \multicolumn{2}{|c|}{ Metabolic state } & \multirow[b]{2}{*}{$\begin{array}{c}\text { Overfed } \\
\text { HS2 at } 24 \mathrm{~h}\end{array}$} \\
\hline & $\begin{array}{c}\text { Healthy } \\
\text { HSl at } 24 \mathrm{~h}\end{array}$ & $\begin{array}{c}\text { Starved } \\
\text { HS1 at } 48 \mathrm{~h}\end{array}$ & \\
\hline PLFA/PLEth & $14.5(2.4)$ & $22.4(4.7)^{*}$ & $1.7(0.5)^{*}$ \\
\hline PHA/PL & $0.30(0.11)$ & $0.28(0.07)$ & $0.42(0.08)$ \\
\hline TG/PL & $0.18(0.03)$ & $0.06(0.01)^{*}$ & $0.04(0.04)$ \\
\hline
\end{tabular}

Abbreviations: PLFA $/$ PLEth $=$ polar lipid fatty acids to ethers. PHA $/ \mathrm{PL}=$ poly $-\beta$-hydroxyalkanoate to total polar lipid. $\mathrm{TG} / \mathrm{PL}=$ triglyceride to total polar lipid.

\subsection{Microbial metabolic status measures}

The ratio of radiolabel incorporated into eubacterial and eukaryotic PLFA to that into archaebacterial PLEth (PLFA/PLEth, Table 1) showed a significant difference between the healthy and starved and between the healthy and overfed conditions. PHA label divided by polar lipid label (PHA/PL, Table 1) showed no significant difference between the treatments. For the ratio of triglyceride label to polar lipid label (TG/PL, Table 1), both the differences were significant.

\section{DISCUSSION}

The successful reproduction of the in situ methane production rates within the pressure tube microcosms supports the contention that they are a valid model of the reactor's behavior (Fig. 1A). The apparent difference between the

Table 2. Summary of the effects of starvation and overfeeding on the high solids digesters relative to the healthy digester. Significant differences were tested for at the $P=0.05$ level

\begin{tabular}{lcc}
\hline & Starved & Overfed \\
\hline Methane production & $\downarrow$ & $\downarrow \downarrow$ \\
Digester pH & $\approx$ & $\downarrow$ \\
Ammonia concentration & $\downarrow$ & $\uparrow$ \\
Acetate concentration & $\approx$ & $\uparrow$ \\
\hline Turnover rate for acetate & $\downarrow \downarrow$ & $\downarrow$ \\
Rate of label incorporation into: & & \\
$\quad$ Total lipid & $\uparrow$ & $\downarrow \downarrow$ \\
$\quad$ Methane & $\downarrow \downarrow$ & $\downarrow \downarrow$ \\
Carbon dioxide & $\downarrow$ & $\downarrow$ \\
\hline Ratio of label into: & & \\
$\quad$ Fatty acids to ethers & $\uparrow \uparrow$ & $\downarrow \downarrow$ \\
PHA to polar lipid & $\approx$ & $\uparrow$ \\
TG to polar lipid & $\downarrow \downarrow$ & $\downarrow \downarrow$ \\
\hline
\end{tabular}

Symbols, relative to the healthy HSl at $24 \mathrm{~h}$ after feeding:

$\downarrow \downarrow=$ significantly less than.

$\downarrow=$ less than.

$\uparrow \uparrow=$ significantly greater than.

$\uparrow=$ greater than.

$\approx=$ approximately equal to. 
rates measured at $48 \mathrm{~h}$ after feeding HSl was an artifact due to the different time resolution of the 2 techniques. The methane production measured on the reactor was averaged over between 24 and $48 \mathrm{~h}$ after feeding, while the rate in the pressure tube was measured between 48 and $51 \mathrm{~h}$ after feeding.

HS1 at $24 \mathrm{~h}$ after feeding exemplified the healthy state of the high-solids digester. Its methane production rate, $k_{\mathrm{Ac}}, k_{\mathrm{CH} 4}$, and $k_{\mathrm{CO} 2}$ (Fig. 1A, 2A, 2C, and 2D, respectively) were all the highest of the 5 treatments tested. Comparison of this sampling point with the starved HS1 at $48 \mathrm{~h}$ after feeding and with the overfed digester HS2 at maximum gas production is summarized in Table 2.

During 60 days of operation of HS1, by $48 \mathrm{~h}$ after feeding (starved condition) the feed was nearly exhausted and methane production much decreased, ${ }^{13}$ as was found in this experiment. The $\mathrm{pH}$, and ammonia and acetate concentrations, however, were relatively unchanged (Fig. 1B and $D$ ), indicating that the digester design maintains a stable environment for the microbial community during feedstock limitation. The lower ammonia concentration is presumably due to nitrogen utilization for cell growth. The rate constants $k_{\mathrm{Ac}}, k_{\mathrm{CH} 4}$, and $k_{\mathrm{CO} 2}$ were all significantly less than the healthy samples at maximum gas production $(24 \mathrm{~h})$, indicating the lower metabolic rate during feedstock limitation. The lowest value for $k_{\mathrm{TL}}$ occurred with the highest level of dissolved substrate and the highest value with the exhaustion of the feed. $k_{\mathrm{TL}}$ represents the competition between acetate and soluble substrate from the feed for entry to the lipid synthesis pathways. When starved, the microbiota of HS1 had a much higher rate of acetate incorporation into lipids, $k_{\mathrm{TL}}$, than when healthy. We interpreted this result as a decrease in precursor pool size, and thus lower isotope dilution, during feedstock limitation.

The same effect was seen in PLFA/PLEth, the ratio of label into fatty acids to that incorporated into ethers. Methanogens do not utilize any carbon source more complex than acetate. ${ }^{22}$ The sugars derived from the feed competed with acetate for entry to the eubacterial lipid synthesis pathways, but could not enter the methanogen pathways.

The ratio PHA/PL did not change with digester starvation. PHA is a carbon and energy storage polymer produced when some nutrient other than carbon and energy sources limit growth. ${ }^{19}$ The starved digester, however, was starved for carbon and energy substrates. It had been supplemented with minerals and with nitrogen as ammonia. Triglycerides serve the same function in micro-eukaryotes as PHA does in eubacteria. ${ }^{12}$ The large decrease in the TG/PL ratio in the starved sample was probably due to utilization of triglyceride during starvation rather than storage during the healthy period.

The comparison of the overfed with the healthy digester is much different from the comparison of the starved and healthy (Table 2). In the overfed digester, the $\mathrm{pH}$ was lower, due to non-utilization of volatile fatty acids released by fermentation (e.g. acetate, Fig. 1D). The ammonia and acetate concentrations were both greater in the overfed than in the healthy digester (Fig. 1C, D). In addition to the high, toxic concentrations of acetate and ammonia, the overfed $\mathrm{HS} 2$ contained $5.5 \mathrm{~g}$ propionate per $\mathrm{kg}$ digester contents. ${ }^{13}$ All of the rates measured were lower in the overfed digester than in the healthy, including the rate of label incorporation into total lipids $-k_{\mathrm{TL}}$. The PLFA/PLEth ratio showed a much lower proportion of the labeled acetate being incorporated into fatty acids in HS2. The general inhibition of metabolic activity in HS2 left more of the preferred eubacterial substrates available for lipid synthesis and less of the eubacterial lipid derived from labeled acetate.

The increase in PHA/PL seen in the overfed digester is due to the lower incorporation of label into PL rather than an increase into PHA. Lipid synthesis for growth was inhibited more than PHA synthesis. TG/PL was much less in the overfed digester, probably due to the effects of the toxic conditions on the micro-eukaryotes responsible for its synthesis.

In addition to the greater activity and metabolic health of HSI, it showed lower variability between replications than HS2. The relative standard derivations for the overfed HS2 were greater than in the healthy HS1 in 6 out of the 8 variables measured. This could be due to greater spatial heterogeneity in the overfed HS2 digester, due to decreased ability to colonize the large amount of feed added 3 times a week.

This work has shown that although both starvation and overfeeding of a methanogenic digester result in a stress which diminishes methane production, the changes within the digester microbial consortia differ. The decrease in methane production in the starved digester was due to depletion of methanogenic substrates 
due to eubacterial carbon limitations. Both the digester environment as well as the microbial metabolic status remained potentially productive given another addition of feedstock. The overfed digester was stressed by a poisoning of its environment due to substrate surplus. This condition would be more difficult to remediate.

Acknowledgements - This research was supported by grants awarded to Dr David White by the Gas Research Institute (No. 5086-260-1303, Dr James Frank, GRI project manager) and the Office of Naval Research (No. N00014-88-K-0489) and to Dr William J. Jewell by the Gas Research Institute (No. 6083-226-0848, Dr T. D. Hayes, GRI project manager). Discussions with Dr Tommy J. Phelps (Institute for Applied Microbiology, University of Tennessee) contributed substantially to this work

\section{REFERENCES}

1. D. C. White, Quantitative physical-chemical characterization of bacterial habitats. In Bacteria in Nature, Vol. 2 (J. Poindexter and E. Leadbetter, Eds), pp. 117-203. Plenum Press, New York (1986).

2. J. M. Henson, P. G. Smith and D. C. White, Examination of thermophilic methane producing digesters by analysis of bacterial lipids. Appl. Env. Microbiol. 50, 1428-1433 (1985).

3. S. K. Schropp, T. J. Phelps, A. T. Mikell and D. C. White, The relationship of eubacterial and methanogenic community structure in anaerobic digesters. In Proc. of the 10th Ann. Conf., Energy from Biomass and Waste, Washington, D.C., April 7-10, 1986 (1988).

4. J. S. Jeris and P. L. McCarty, The biochemistry of methane fermentation using ${ }^{14} \mathrm{C}$ tracers. J. Water. Pollut. Control Fed. 37, 178-192 (1965).

5. S. H. Zinder, Patterns of carbon flow from glucose to methane in a thermophilic anaerobic bioreactor. FEMS Microbiol. Ecol. 38, 243-250 (1986)

6. E. L. Iannotti, R. E. Mueller and J. R. Fischer, Microbiology and biochemistry of methane fermentations. In Biomass Energy Development (W. H. Smith, Ed.), pp. 415-438. Plenum Press, New York (1985).

7. T. J. Phelps, D. B. Hedrick, D. H. Ringelberg, C. B. Fliermans and D. C. White, Utility of radiotracer activity measurements for subsurface microbiology studies. J. Microbial Meth. 9, 15-27 (1989).

8. T. G. Tornebene and T. A. Langworthy, Diphytanyl and dibiphytanyl glycerol ether lipids of methanogenic archaebacteria. Science 203, 51-53 (1979).
9. D. L. Balkwill, F. R. Leach, J. T. Wilson, J. F. McNabb and $D . C$. White, Equivalence of microbial biomass measures based on membrane lipid and cell wall components, adenosine triphosphate, and direct counts in subsurface sediments. Microbial Ecol. 16, 73-84 (1988).

10. J. S. Herron, J. D. King and D. C. White, Recovery of poly- $\beta$-hydroxybutyrate from estuarine microflora. Appl. Environ. Microbiol. 35, 251-257 (1978).

11. E. A. Dawes, Endogenous metabolism and the survival of starved prokaryotes. Symp. Soc. Gen. Microbiol. 40 , 19-53 (1976).

12. M. J. Gehron and D. C. White, Quantitative determination of the nutritional status of detrital microbiota and the grazing fauna by triglyceride glycerol analysis. J. Exp. Mar. Biol. 64, 145-158 (1982).

13. B. K. Richards, R. J. Cummings, W. J. Jewell and F. G. Herndon, High solids anaerobic methane fermentation of sorghum and cellulose. Biomass and Bioenergy 1 , 4)-53 (1991)

14. D. E. Jerger and D. P. Chynoweth, Anaerobic digestion of sorghum biomass. Biomass 14, 99-113 (1987)

15. E. G. Bligh and W. J. Dyer, A rapid method of lipid extraction and purification. Can.J. Biochem. Physiol. 35, 911-917 (1959).

16. D. C. White, W. M. Davis, J. S. Nickels, J. D. King and R. J. Bobbie, Determination of the sedimentary microbial biomass by extractable lipid phosphate. Oecologia 40, 51-62 (1979).

17. D. C. White, G. A. Smith, M. J. Gehron, J. H. Parker, R. H. Findlay, R. F. Martz and H. L. Fredrickson, The groundwater aquifer microbiota: Biomass, community structure, and nutritional status. Dev. Ind. Microbiol. 24, 201-211 (1983).

18. C. A. Mancuso, G. Odham, G. Westerdahl, J. N. Reeve and D. C. White, $\mathrm{C}_{15}, \mathrm{C}_{20}$, and $\mathrm{C}_{25}$ isoprenoid homologues in glycerol diether phospholipids of methanogenic archaebacteria. J. Lipid Res. 26, 1120-1125 (1985).

19. R. H. Findlay, P. C. Pollard, D. J. W. Moriarty and D. C. White, Quantitative determination of microbial activity and community nutritional status in estuarine sediments: Evidence for a disturbance artifact. Can. $J$. Microbiol. 31, 493-498 (1985).

20. B. J. Winer, Statistical Principles in Experimental Design, p. 208. McGraw-Hill, New York (1971).

21. J. Ansbaek and T. H. Blackburn, A method for the analysis of acetate turnover in a coastal marine sediment. Microbial Ecol. 5, 253-264 (1980).

22. W. J. Jones, D. P. Nagle, Jr and W. B. Whitman, Methanogens and the diversity of archaebacteria. Microbiol. Rev. 51, 135-177 (1987). 